\title{
Supporting, Evaluating and Validating Informal Learning. A Social Approach
}

\begin{abstract}
Informal learning has been a global hot topic for the past several years. The growth of the internet and the pervasiveness of computers in everyday life means that a huge part of this informal learning is done through a computer. In the European Union, since the official recognition of informal learning in 1999 with the Bologna Treaty, a number of guidelines and proposals have been published providing techniques and recommendations for translating informal learning outcomes to formal competences. Most of these guidelines depend on an evaluator (internal or external) to oversee and certify the process. In our work, we propose the usage of a more social and dynamic framework for gathering, validating and promoting a learner's digital informal learning. This framework is based primarily on peer interaction and peer assessment instead of employing experts and provides mechanisms for personalized recommendations in order to introduce further informal learning opportunities to the learners. We propose an approach where a learner's evaluation happens organically while other learners adopt the same activities and evaluate them positively or negatively.
\end{abstract}

\section{Keywords}

Informal learning, non-formal learning, e-learning, eLearning, lifelong learning, social learning, validation, evaluation.

\section{INTRODUCTION}

The growth of the Internet during the past couple of decades has defined modern life more than any other recent technological advance. Thanks to the Internet, we enjoy access to global connectivity and all the information that comes as a result. The versatile nature of the Internet has proven to be the ideal conductor for all kinds of information exchange. It provides a dynamic framework that allows for all kinds of communication, whether unidirectional or bidirectional, synchronous or asynchronous, symmetric or asymmetric. Whether provided by specialized digital knowledge platforms or by custom Internet searches, the wealth of information that we have access to is not easily quantifiable. The simple act of aimlessly navigating the Internet can provide an important amount of information. All this information inevitably leads to knowledge, and given the amount of information we are exposed to constantly, this knowledge begins to gain important dimensions that cannot and should not be neglected when examining the competences of individuals.

A result of all this access to information and knowledge, is the emergence of what is called the modern Knowledge Society [1], [2]. Knowledge has always been one of the primary motivators of human progress. The search for answers and the effort put into understanding our surroundings is responsible for the continuous evolution of our species. Today, whether in terms of quality, quantity, general availability and ease of access, knowledge is more present than ever in our everyday life and the Internet is undoubtedly one of the main facilitators of this situation.

This learning potential of the Internet regardless of age and social or financial background, has led to a rising interest in the concept of lifelong learning. A number of organizations, foundations and projects like the University of the Third Age (U3A) [3] and the Lifelong Learning Programme of the European Community [4], are centered in promoting and facilitating continuous learning for all kinds of social, ethnic and economic groups.

The concepts of formal, informal and non-formal learning are tied to that of lifelong learning. Formal learning refers to the education received from a recognized education center that leads to a certification. Everything else is considered either nonformal or informal learning. An example of non-formal learning would be taking private music lessons with a music teacher, while watching a tutorial video on how to cook a particular recipe would be informal learning. For the remainder of this article we will be using the term informal learning (IL) to refer to both informal and non-formal learning since in the context of our approach they present the same characteristics and challenges.

Since the Bologna treaty, the European Council, recognizing the importance of non-formal and informal learning, has been actively trying to define a set of guidelines for their validation, with a first set of guidelines being published in 2004 [5]. The goal of the European Council is to quantify which skills are available in the European workforce in an effort to promote better matching between the demand and the availability of skills within Europe.

Furthermore, a lot of documentation exists on the active role of Information and Communication Technologies (ICTs) in lifelong learning initiatives. Punie et al. [6] present a collection of evidence that modern education is heavily impacted by ICTs and come to the conclusion [7] that non-formal, informal and adult learning are becoming important for the future of learning.

In many cases, the distinction among formal, non-formal and informal education is difficult to make as the lines that separate them become blurred in the sense that we end up participating in more than one of these types of learning at the same time. For this reason we consider it important to take into account the effort put into learning outside the formal structures and evaluate individuals accordingly. It would be shortsighted to continue evaluating individuals solely based on their formally 
attained degrees when we are exposed daily to so much information that we are essentially constantly taking part in informal learning activities.

This raises the following question: Can the knowledge obtained through non-formal and informal means be quantified and evaluated in order to be formalized and recognized within the competences of a curriculum?

While describing informal learning activities is a relatively simple process, it is much more complex to define a model that describes the actual knowledge we acquire with these activities. Concretely, the main difficulty inherent to the informal learning process is the validation and evaluation of the acquisition of this informal knowledge.

The TRAILER (Tagging, Recognition and Acknowledgement of Informal Learning Experiences) project that was funded by the Lifelong Learning Programme of the European Union [8][9][10] tried to tackle this issue. Its goal was to provide a methodology and a software platform that would facilitate communication of informal learning experiences between learners, employees and businesses.

In this work, we propose an approach for validating IL that is not based upon an unwieldy list of competences or solely upon a strict rule set. We are proposing a social-oriented framework that on top of a set of rules and predefined competences, uses social engineering and peer interaction to not only validate, but to also promote informal learning. To the best of our knowledge, there are no other works in the literature that take this approach.

The rest of this article is organized as follows: Section 2 presents a review of the state of the art centered on EU initiatives, tools that aid IL, the social aspect of IL and work done on competences. Section 3 presents a list of challenges that concern the informal learning validation process. Section 4 presents our proposal for a social approach to the issue of validation and evaluation. Section 5 analyzes the benefits we view to our approach. Section 6 provides an analysis of the perceived risks to implementing our proposal. Section 7 details our intended evaluation procedure. Finally, in section 8 we present our conclusions.

\section{STATE-OF-THE-ART}

\subsection{European Union Initiatives}

The European Union has been actively investing in the subject of informal learning for a number of years. The Bologna treaty that was signed in 1999 [11] recognized informal learning as a basic element of lifelong learning. Since then, there have been a number of European initiatives for validating informal and non-formal learning. The European Centre for the Development of Vocational Training (CEDEFOP) [12], gathers experiences of informal learning from the different European countries and tries to define European qualifications through tools like the European Qualifications Framework (EQF) [13] which is a common reference framework that aims to link the qualification systems of the different European countries.

In order to support informal learning, the European Union defined it as an important part of its Lifelong Learning Programme [4]. The program acknowledges that European countries are increasingly aware that an individual's knowledge and qualifications in terms of skills and competences are heavily defined by their informal and non-formal learning activities. For this reason there is an ongoing effort searching for solutions on the problem of validation of such learning experiences. In order to correctly validate them these experiences first need to be identified, documented and assessed. The Inventory project [14] provides a concise list of the situation on validating informal learning in 30 EU countries. From all the documented experience, the authors distinguish eight use-cases that they consider to be good practice. The authors conclude that in general, the EU countries have taken steps towards validating informal learning, but the mechanisms employed by the different countries lack cohesion and coordination, complicating the communication of competences gained through informal learning among the different countries.

CEDEFOP published in 2009 a set of guidelines for validating non-formal and informal learning [5]. This document is presented as a practical tool containing a framework of guidelines to be applied voluntarily. The authors believe that a common framework for validation will serve as a way to promote non-formal and informal learning among the European citizens, since it will benefit them with recognition of their efforts at a European level, instead of just a national one. Validation is considered on four different levels or perspectives: European, national, organizational and personal. All four are considered equally important and should be taken into account throughout the validation process. The authors argue that nonformal and informal learning can be validated using the same standards and benchmarks as formal learning. According to them, this is also a good way to increase the legitimacy of informal learning. Broad acceptance of the validation methodology is essential for it to have any chance of success.

\subsection{Informal Learning Tools}

The recognized importance of informal learning has inevitably led to the development of a number of tools that aim to aid and promote the concept and assist the learners with their activities. 
Some of these tools are designed as platforms for promoting and facilitating informal learning. Examples of such platforms are FREE (Fostering Return to Employment through Entrepreneurship, Innovation and Creativity) [17] and IBAK [18]. FREE is an interactive tool aimed towards people working with the unemployed. Its aim is to help these people improve their hard and soft skills so that they may provide a better service to the unemployed. Similarly, IBAK is an EU funded project addressed to professionals working in the field of lifelong learning and aims to help adult education institution by providing a framework for identifying, assessing and recognizing informally acquired competences.

Apart from platforms providing assistance to those that work in adult and lifelong learning, there are those that aim at recording and identifying the competences an individual has acquired through informal learning. These tools are usually portfolios or similar software like TENCompetence [19][20], Mahara [21][22][23], Mozilla's OpenBadges [24] and Degreed [25]. ePortfolios are regarded among the ideal tools for lifelong learning [26].

Mahara is an ePortfolio software in the traditional sense of the term. Users can gather all their titles, degrees or competences whether obtained through formal means or not. Such a platform can help users give visibility to their informal learning activities by presenting them alongside their formal learning and in an equal format. However, there is always a risk of not being able to adequately represent competences acquired through informal means precisely due to the potential lack of structure of such activities. Such a case would be a portfolio that requires a rigid structure when defining activities and competences.

TENCompetence is a European open source project aiming to provide an infrastructure [27] that fosters lifelong learning. TENCompetence is more focused on the competences an individual obtains throughout their life. For this reason, it provides tools for creating a competence profile. To serve as a desktop tool for the project, the TENCompetence ePortfolio was proposed in order to provide the learners with a tool they could use to organize their competence profile. The Personal Competence Manager [28] was developed as a result.

OpenBadges and Degreed are trying to provide some more tangible reward to a learner's informal learning activities in the form of badges or scores respectively. This provides an additional incentive for the learners to register their activities since they are getting an immediate reward. Despite this reward being more psychological than actually important, it has been proven to work very well as a way to keep users coming back and try to earn more of the available awards. Keeping an inventory of activities can be a tedious undertaking in itself, and any small reward for doing it can make a lot of difference. Moreover, the ability to be able to compare these rewards to those of your contacts creates a healthy competition that further fosters effort put into informal learning.

The TRAILER project proposed the creation of a portfolio for informal learning activities where the learners can create showcases of their informal learning and have them be visible to their institution or company. The platform also provides a decision support system (DSS) for employers to be in touch with the informal learning within their company [29]. TRAILER makes use of cloud services [30] in order to provide a modern and accessible architecture that makes it easy for learners to manage their activity.

Finally, apart from specific tools, some mention should be given to IT technologies that work to the benefit of IL [31]. There are numerous studies that look into the advantages offered to informal distance learning by Web 2.0 services [32][33][34][35][36] as well as mobile technologies [37]. The authors mention blogs, wikis, messenger software, YouTube and Facebook as examples of Web 2.0 tools with great IL potential that are very popular especially among younger users. Similarly in [38], the authors discuss the role of social networks in education, a study they conducted while adapting their LMS at the University of Trento to Web 2.0 services. They stress the importance of providing tools for collaborative learning spaces that foster communication and active participation. In [39] the authors explain the benefits of collaborative tagging in mentoring tools enabled by the semantic technologies of Web 2.0, while Conde et al. in [40] describe how to enhance an LMS by incorporating external (formal and informal) activities carried out in 2.0 tools.

\subsection{Socializing Informal Learning}

The bibliography also echoes the important role of social networks and Virtual Learning Environments (VLEs) in facilitating informal learning. Halliday-Wynes and Beddie [16] argue that the advent of new technologies has led to an evolution of the learning environment and that VLEs, multimedia and social networking tools have given unprecedented access to learning material. But it is not only the access to the material that acts as a catalyst to the volume of informal learning. García-Peñalvo et al. [41][42] argue the importance of knowledge exchange in the Social Web and the influence it has to informal learning, using as an example the MyElvin Social Network for language practice. The interconnection opportunities that exist with the VLEs and the social networks are a very important factor in all kinds of learning. VLEs will most probably connect individuals to their peers since they normally exist to support a relatively homogeneous user base, but more extensive social networks like Facebook, Google Plus and Twitter provide a connection to a hugely heterogeneous network of people with equally disperse opportunities for learning. 
Social networks like Facebook have become important platforms, both in the sense of digital meeting places for learners potentially geographically dispersed [43][44], as well as resource providers for IL [45]. As a result, a number of researchers are conducting studies on modeling social learning and knowledge building [46]. For example, the extend of Facebook's influence in education, coupled with the fact that it has been observed that students are more likely to express themselves on a social network than in an LMS [47], has led many education institutions to establish a presence there in order to be in touch with their students [48]. Following this trend, a number of teaching institutions opt to develop their own social network to be used by their students.

Whitty et al. propose an informal learning framework built in Facebook that promote a moderated collaborative constructivism ecosystem where learners can create learning elements, expand on existing ones, discuss, ask and in general interact with the moderator (teacher) and their peers [49].

Casagranda et al. in [50] explain the social learning platform Online Communities developed in the University of Trento. The platform provides a personal learning environment (PLE) for each learner who in turn can choose what parts of this PLE to import into Online Communities. The platform is designed to provide support for lifelong learning with the virtual community templates being general enough to adapt to different organization styles.

Roreger and Schmidt propose to socialize online learning by profiling the learners' behavior and identify parameters for successful team building [51]. These parameters include learning style and knowledge level. According to the authors, to be successful, the LMS and the social network that form the social learning platform should be intertwined and all learning material should be available directly from the social network.

Shi et al. argue the importance of profiles in social learning tools as means to promote social constructivism, competitive learning, self-regulation and adaptive learning [52]. according to the authors, having access to other users' profiles as well as having one's profile accessible by others is very profitable for both the constructivist and the connectivist parts of a user's learning process.

\subsection{Personalized recommendations}

Santos and Boticario detail a recommender model that allows managing recommendations at the course design time, that includes an explanation for each recommendation and that requests feedback on each recommendation [53]. Similarly in a smaller scale environment, Colomo-Palacios et al. in [39] propose the IM-TAG tool that can uses collaborative tagging of blog posts to recommend contents to users based on their profiles. The system is comprised of three engines: (1) the annotation engine that translates user posts and comments to semantic information, (2) the rating engine that gathers user ratings for the contents and (3) the recommendation engine that is based on a Jena Rules engine to perform the recommendation tasks.

A tool or technique that can provide a basis for a recommendation system is collaborative tagging. In traditional tagging environments like Delicious and Flickr, tags help users discover content that they otherwise would not [54]. Macgregor and McCulloch in [55] look into collaborative tagging as a tool for discovering learning resources. They comment on the two approaches of tagging: controlled vocabulary and collaborative, and their usefulness that is relatively context-sensitive. A collaborative tagging approach may not make it easier to the learners to find what they are looking for, but may bring to their attention other learning resources that they were unaware of. Tools like tag clouds showing the most popular topics in a learner's network is also very efficient in fomenting further IL [56].

Drachsler, Manouselis et al. [57][58] suggest mixing usual recommender system criteria (accuracy, coverage, performance) with measures of educational research like learner interests, history and behavior while Lai et al. propose a formula for calculating the return on investment (ROI) of a learning activity based on its relevance, importance, popularity, average rating, its type and its size [59]. This ROI indicator, can then be used to recommend a learner the most beneficial activities relevant to their profile.

Although not strictly a resource recommendation feature, in [60] the authors detail a person tagging mechanism incorporated into the MATURE project. This mechanism searches for the people within the organization that closest match the search criteria and are potentially the best resources to consult for information on the particular subject. The authors argue the importance of this process in building strong knowledge social networks within a company.

\subsection{Peer Assessment}

Generally in an informal learning context there are no compulsory assessment procedures. On the contrary, whatever assessment there is, it is mostly of an informal and collective type. Apart from assessment coming directly from like-minded informal learners, self-assessment also tends to be based on feedback received from others [61]. Moreover, due to the unstructured nature of IL, a lot of learners find beneficial the presence of a "facilitator" that follows their activity and regularly intervenes either to motivate or to assess them [62].

One of the cornerstones of building a peer assessment system is proposing the quality measure for the assessments. HartDevidson et al. [63] identify 3 main challenges (1) inadequate workflow and data models for capturing the review activity, 
(2) lack of quality indicators and measures and (3) building a profile for the assessors. The authors propose helpfulness as the best indicator of a review's or assessment's quality. To accommodate this indicator, a peer review process should provide the tools for the reviewer to provide their review and the learner and other reviewers to interact with it (either by further suggestions or endorsements).

An important issue to take into account when considering a peer assessment model in a social tool is the issue of privacy and confidentiality, or the lack thereof [64]. This becomes even more critical when considering IL assessment within a formal context, i.e. a school or a university, where these issues tend to be heavily regulated and respected.

\subsection{Competences}

Wrapping up this section, identifying and validating informal learning relies on translating all the knowledge gathered through informal means to actual competences. It is these competences that hold the real value for the learner and for all the potential employers. the term competence is defined as the skills and the abilities that characterize an individual or a group [65][66][67]. Along the same lines, Sampson and Fytros [68], make a distinction between competences and competencies. They use the term competence to refer to a set of personal characteristics that are used to perform an activity in a certain context. According to the authors, competence can refer to skills, knowledge, attitude, etc. On the other hand, competency is used as a synonym for skill. Le Deist and Winterton [69], describe 'competence' as referring to functional areas and 'competency' as referring to behavioral areas, noting however that usage is inconsistent throughout the literature. Within the $\mathrm{EQF}$ competence is defined as the ability to use knowledge, skills and personal ability in a responsible and autonomous way. It refers to both personal and professional development.

The International Labour Organization (ILO) through the International Standard Classification of Occupation (ISCO), provide a basis for international classification of occupation. Their latest revision ISCO-08 [70][71], dated December 2007 is used as a reference by a lot of countries looking to improve their alignment with the international standards. However, more than a list of competences, ISCO-08 is a comprehensive list of job titles and specific tasks related to each job.

In the literature, we find a number of specifications for competence description:

- IMS RDCEO (Reusable Definition of Competency or Educational Objective Specification) [72], provides an information model that permits the exchange of competency definitions between various systems (learning, HR, repositories, portfolios, etc.).

- IEEE RCD [73] stands for Reusable Components Definition. The purpose of this standard is to provide a universally acceptable definition for competency. IEEE RCD provides a specification for defining competences by specifying the mandatory and optional data required.

- HR Open Standards (formerly HR-XML) [74]. This organization develops standards for vocabularies and schemes for human resources.

For a competence framework to have meaning, the notion of competence must be global, non-historic and non-contextual in nature [75]. Otherwise the translation of competences from one national qualifications framework to another will be impossible [76].

In [77], the authors propose a validation mechanism for informal workplace learning using carefully constructed questionnaires for the learners. These questionnaires are subsequently analyzed using exploratory and confirmatory factor analysis in order to reveal the structure of the outcomes within the target group and validate it.

\section{VALIDATION CHALLENGES}

The inconsistent, abstract and contextual nature of non-formal and informal learning means that their validation is a complicated issue. The natural tendency is to translate competences acquired through non-formal and informal means to formal ones and try to apply the same validation rules and methods. These methods however tend to be strictly defined and structured and are in many cases unsuitable for evaluating the mostly unstructured activities of informal learning. This relies on the traditional challenge of structuring and formalizing entities that are unstructured and heterogeneous by nature, in order to analyze or process them by means of quantitative or qualitative techniques.

There are a number of identified factors that complicate the validation process of informal learning, especially in international environments where different mechanisms and legislations come into play.

1. Long unwieldy competence lists. The existing competence lists like ISCO-08 need to encompass all possible scenarios. This results in having to shift through huge lists of overly specific competences in order to apply one to an activity without in many cases being certain that it is the most appropriate one.

2. Need for a third-party examiner or observer. Usually, evaluation and validation of a learning process requires the presence of an observer that follows the methods that the learners use. However, in the case of informal learning activities, their unstructured nature and the potential irregularity of the schedule practically rule out efficient observation. 
3. Many external stakeholders exerting pressure. As long as there is value perceived in the validation of informal learning, there will be a number of stakeholders interested in participating in the validation process. These stakeholders usually range from national or regional public entities, to private organizations, oftentimes applying different criteria, different requirements, monetary or otherwise and different interests or purposes. These differences complicate the coordination in a national or international level and put in question the validity of the evaluations they offer.

4. Heterogeneity of IL process. By its nature, informal learning is heterogeneous and unstructured. This means that it is possible for two learners to achieve the same level of knowledge on a topic following different activity paths and schedules. Whether the validation process should account for these differences despite the identical end results is a very interesting debate.

5. Internet-based informal learning. The issue is complicated even further when the informal learning activities are Internet based. Informal learning resources may come from a vast selection of sources all over the world. Different backgrounds, cultures, notions and beliefs come into play when analyzing the informal learning process. The capability of a single organization to analyze the validity and value of all these resources is questionable at best.

6. Differences among countries. Even in formal learning contexts, different countries use different metrics and procedures for their evaluations. The same is true for informal learning. For this reason it is very complicated to have a coordinated effort for the validation of non-formal and informal learning.

7. Experience. The accuracy of validation and evaluation is subject to the experience of the evaluator. It would be an error to ignore the experience factor when designing the evaluation aspects of the framework.

These factors raise the question of whether applying a validation methodology derived from formal learning experiences is the most efficient and effective way to go about validating non-formal and informal learning.

\section{A SOCIAL APPROACH}

The experience we gathered during the execution of the TRAILER project has led us to consider alternative approaches to the issue of validating non-formal and informal learning. What we propose in this article, is to provide a social framework that will center on peer collaboration and recommendation in order to build a knowledge base not only capable of producing an evaluation of a learner's activity and their progression towards attaining certain competences, but to also provide recommendations based on the activity of their peers.

The idea is that learners will have their private space where they can store all the ILAs they undertake, tag them appropriately and attach them to a certain competence if it is relevant. If they wish, they can make their activities public to everyone or to a certain group of people (e.g. the people they are related to professionally). These public activities will be ratable, commented upon, followed or adopted by the other members of the community. The traffic and the ratings generated for each activity is a good starting point for its evaluation.

The platform will implement a collaborative tagging framework where tags used by different learners for the same ILAs will be gathered for a more complete characterization of the different activities. These tags, apart from providing the different dimensions of each activity will also be useful for creating a tag cloud that will provide insight into the learning trends and will show users what activities are popular at any given time.

Apart from the active user participation, the platform will implement a recommendation system that will recommend to a learner, activities undertaken by others with similar informal learning portfolios. The collaborative tagging framework mentioned above is sure to play an important part in the design of the recommendation algorithm where similar tags can be used to find similar activities to propose for further learning. Moreover, ILAs can be both positively rated for the learner to look into, or negatively rated, in order to be avoided. This feature should help further promote informal learning by exposing potentially unknown sources and activities to the learners as well as encouraging them .

For use within an institution or a company, the platform takes its clues from the one designed for the TRAILER project of the European Lifelong Learning Programme. Learners (in this case employees) choose to make public to the employers and their colleagues certain ILAs. Colleagues and employers get the chance to evaluate these activities. Employers gain a better understanding of the competences existing within the company and are in a position to make better management decisions.

\section{EXPECTED BENEFITS}

We expect to observe a number of beneficial outcomes from this proposed social approach to informal learning.

- Motivation. The ability to follow the activities of other people, see what they are learning and how, is a motivating factor for one's learning activity. It is in the human nature to compare one's self to their peers and try to keep up or to outdo them.

- Evaluation. Learners can see the comments and evaluation their activities are getting. This helps them know how well they are doing, if they are on the right path, if others regard their learning as interesting or useful, etc. 
- Collaboration. Two or more learners can use the platform to coordinate their learning activities. They could divide topics among themselves and then interchange experiences in private or they could center on the same topic undertaking the same activities and sharing the same end goal.

- New resources. The recommendation feature of the platform can help learners find resources and activities they did not know about previously. They can also browse the activities of people working on the same competences.

- Transparency. Access to a learner's activities and not just to a declared competence adds an important degree of transparency to their curriculum. The number and quality of informal learning activities related to a competence is a transparent metric for determining a competence's mastery level.

\section{EXISTING RISKS}

In parallel to all the benefits that the social approach may have, there are a number of risks that should be avoided in order to have the platform be a tool that supports and promotes informal learning and not one that strictly controls it.

- Employee control tool. In an institution or company environment there is always the risk of having every progressregistering platform be turned to a tool to control the employees. Especially in the workplace, there is a big risk of having people being discriminated due to their informal learning portfolios, or lack thereof.

- Strict evaluation platform. The objective of our proposal is a platform that fosters interaction and promotes informal learning. The evaluation mechanisms should be robust, but discreet enough to not overshadow the important aspect of the platform, which is informal learning itself.

- Moderation mechanisms. As any social platform, there are bound to be rivalries, discussions, differences, etc. The evaluation algorithms should be carefully designed so that if a learner evaluates unfairly the activities of a peer, their evaluation will not have a major impact.

- Irrelevant social interactions. Similarly to the above point, great care must be put into deciding what types of interactions will be allowed on the platform. After all, this should be an informal learning platform and not a social interaction tool. Giving too much liberty in how learners can interact with their peers may end up having negative effects to the nature of those interactions.

- Informal learning becomes mandatory. This risk is a more generalized version of the first point of this list. The whole idea of making informal learning visible and valid for a curriculum entails the risk of converting it into something mandatory instead of an added bonus.

- Competence lists. Finally, a risk that we identified during our involvement in the TRAILER project was the unwieldy official competence lists provided international standards organizations. The absence of a cohesive and intuitive list can break the entire platform. If the users have to shift through hundreds of competences in order to identify the most appropriate one for their activity, they will quickly abandon the platform. On the other hand, if the users have absolute freedom in defining their own competences, the platform will end up having to juggle an equally huge list of ill-defined competences with many of them referring to the same concept.

All these risks present challenges that will have to be tackled at the design phase of the informal learning evaluation and validation framework.

\section{FRAMEWORK EVALUATION}

We are following the action research methodology [78][79] for the design and development of our proposal. Action research consists in solving a particular problem by directly working on it and do a number of iterations of development and evaluation. For the evaluation part, we are planning on organizing a couple of rounds of focus tests, where real users from the academia and from the private sector will be able to get their hands on the platform and use it for a short period of time (2-4 weeks). For recruiting users, we have direct contact with UPC-BarcelonaTech and the University of Salamanca (USAL) for academic users and a number of small and medium enterprises (SMEs) in the area of Barcelona that have participated in tests of previous projects of ours that are willing to help us recruiting users from the private sector. After each round, we will ask them to answer some questions evaluating the platform. These questions will focus in a number of indicators for the platform like:

- Usability: intuitive and responsive interface, efficient and clear presentation of information,

- Induced overhead for the learners: time dedication required for keeping the portfolio up to date,

- Perceived benefits from using the platform.

Apart from the answers to the questionnaires, the usage statistics that we will record for the duration of the tests will provide further data for our evaluation. These metrics include, but are not limited to:

- Number of visits of a learner,

- Time spent per visit,

- Number of ILAs introduced per learner,

- Number of ILAs edited after being introduced in the platform, 
- Number of showcases created,

- Number of recommendations adopted,

- Number of social interactions,

- Number of direct evaluations of activities,

Figure 1 shows the development timeline for the platform where we contemplate the two month-long pilot phases with an additional period of two to four weeks after each pilot for data analysis before we continue with the next round of development.

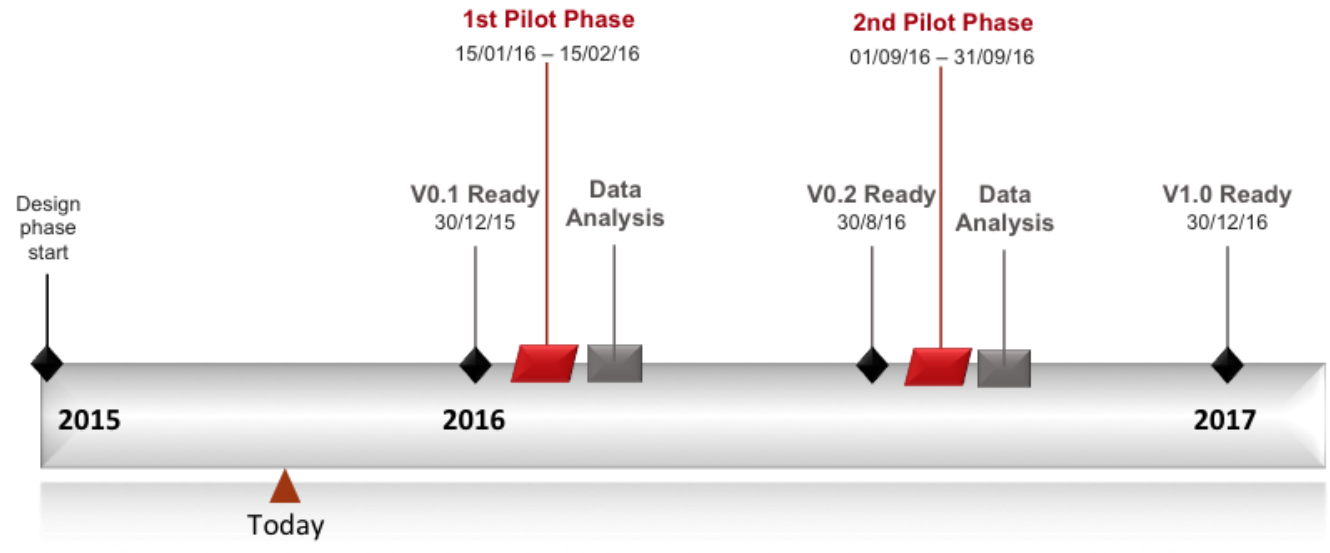

Figure 1: Planned timeline for the development of the platform

Again, our experience with the TRAILER project has shown us that these two sources of information can provide a fairly accurate depiction of the learners' perception of the framework, both in terms of interest in the process and the platform's usability.

\section{CONCLUSIONS}

In conclusion, we have established the importance of informal learning and its wide acceptance from institutions and governments. As a consequence to that we can find many proposals in the literature for its validation. However, these proposals either offer theoretical guidelines for projecting informal learning experiences to formal learning and applying the same rules that are applied to formal learning, or come in the form of tools that offer virtual prizes for learners that register certain activities. To the best of our knowledge there has not been a proposal to evaluate informal learning using the characteristics and the popularity of the activities themselves as a

Our proposal comes in the form of an informal learning social collaboration network where learners choose what to expose where and give and receive useful feedback for their activities as well as recommendations for further exploration.

We believe that our proposal achieves more than the rest by using a flexible peer-driven evaluation and validation framework and by offering a recommendation mechanism that helps the learners discover additional activities related to their informal learning curricula.

\section{REFERENCES}

[1] Stehr, Nico. Knowledge societies. Blackwell Publishing Ltd, 1994.

[2] Mansell, Robin, and Uta Wehn, eds. Knowledge societies: Information technology for sustainable development. United Nations Publications, 1998.

[3] University of the Third Age. http://www.u3a.org.uk/ [Online; accessed 25-March-2015].

[4] E. Commission,The Lifelong Learning Programme, 2007 - 2013. http://ec.europa.eu/education/tools/llp_en.htm [Online; accessed 25-March-2015].

[5] E. C. for the Development of Vocational Training, European guidelines for validating non-formal and informal learning. Office for Official Publications of the European Communities, 2009.

[6] Y. Punie, D. Zinnbauer, and M. Cabrera, A Review of the Impact of ICT on Learning, JRC 47246 ed., 2008.

[7] Y. Punie, M. Cabrera, M. Bogdanowicz, D. Zinnbauer, and E. Navajas, The Future of ICT and Learning in the Knowledge Society: Report on a Joint DG JRC-DG EAC Workshop Held in Seville. Luxembourg: Office for Official Publications of the European Communities, 2006.

[8] García-Peñalvo, Francisco J., Miguel Á. Conde, Valentina Zangrando, Alicia García-Holgado, Antón M. Seoane, Marc Alier, Nikolas Galanis et al. TRAILER project (Tagging, recognition, acknowledgment of informal learning 
experiences). A Methodology to make learners' informal learning activities visible to the institutions. Journal of Universal Computer Science 19, no. 11 (2013): 1661-1683.

[9] Peñalvo, Francisco José García, Valentina Zangrando, Alicia García Holgado, M. A. C. Gonzalez, AM Seone Pardo, D. Griffiths, M. A. Forment et al. TRAILER project overview: Tagging, recognition and acknowledgment of informal learning experiences. In Computers in Education (SIIE), 2012 International Symposium on, pp. 1-6. IEEE, 2012.

[10] Viegas, Maria C., Maria A. Marques, Gustavo R. Alves, Valentina Zangandro, Nikolas Galanis, Francis Brouns, José Janssen et al. Using TRAILER tool for Managing Informal Learning in academic and professional contexts: the learners' perspective. In Proceedings of the First International Conference on Technological Ecosystem for Enhancing Multiculturality (TEEM '13). ACM, New York, NY, USA, 529-534.

[11]E. E. H. E. Area, Towards the European higher education area, in Conference of Ministers responsible for Higher Education in 29 European countries, Bologna, Italy, 1999.

[12] CEDEFOP: European Centre for the Development of Vocational Training. http://www.cedefop.europa.eu/ [Online; accessed 25-March-2015].

[13]European qualifications framework. https://ec.europa.eu/ploteus/ [Online; accessed 25-March-2015].

[14]M. S. Otero, A. McCoshan, and K. Junge, European inventory on validation of non-formal and informal learning, A Final Report to DG Education \& Culture of the European Commission. ECOTEC Research and Consulting Limited. Birmingham, 2005.

[15] M. Dale, J. Bell, and G. Britain, Informal learning in the workplace. Department for Education and Employment London, 1999.

[16] S. Halliday-Wynes and F. Beddie, Informal learning, 2009.

[17]FREE: Fostering Return to Employment through Entrepreneurship, Innovation and Creativity. [Online; accessed 25March-2015].

[18]IBAK: Identification, assessment and recognition of informally acquired competences. [Online; accessed 25-March2015].

[19] A. Berlanga, P. Sloep, F. Brouns, M. Bitter-Rijpkema, and R. Koper, Towards a TENCompetence eportfolio. International Journal of Emerging Technologies in Learning (iJET), [S.1.], v. 3, p. pp. 24-28, jul. 2008. ISSN 1863-0383.

[20] J. Schoonenboom, H. Sligte, A. Moghnieh, D. Hern_andez-Leo, K. Stefanov, C. Glahn, M. Specht, and R. Lemmers, Supporting life-long competence development using the TENCompetence infrastructure: a first experiment. International Journal of Emerging Technologies in Learning (Special Issue), 3(1), 53-59. July, 2008.

[21] Mahara: Open source e-portfolios. https://mahara.org/ [Online; accessed 25-March-2015].

[22]P. Gerbic and M. Maher, Collaborative self-study supporting new technology: The mahara e-portfolio project, Proceedings of ASCILITE Melbourne, pp. 320\{324, 2008.

[23] M. Brown, B. Anderson, M. Simpson, and G. Suddaby, Showcasing mahara: A new open source e-portfolio, Proceedings of ASCILITE Singapore, pp. 82-84, 2007.

[24] Mozilla: OpenBadges. http://openbadges.org/ [Online; accessed 25-March-2015].

[25]Degreed. https://degreed.com/ [Online; accessed 25-March-2015].

[26] J. Fournier, C. Lane, and S. Corbett, The journey to best practices: Results of a two-year study of e-portfolio implementation in beginning composition courses, in World Conference on Educational Multimedia, Hypermedia and Telecommunications, vol. 2007, pp. 2008-2016, 2007.

[27]R. Koper and M. Specht, TENCompetence: Life-long competence development and learning. Innovative Approaches for Learning and Knowledge Sharing Lecture Notes in Computer Science Volume 4227, 2006, pp 621-627.

[28] Vogten, H., Koper, R., Martens, H., \& Van Bruggen, J. (2008). Using the personal competence manager as a complementary approach to IMS learning design authoring. Interactive Learning Environments, 16(1), 83-100.

[29] García-Peñalvo, F. J., \& Conde, M. Á. (2014). Using informal learning for business decision making and knowledge management. Journal of Business Research, 67(5), 686-691.

[30] García-Peñalvo, F. J., Johnson, M., Ribeiro Alves, G., \& Minovic, M. (2014). Informal learning recognition through a cloud ecosystem. Future Generation Computer Systems, 32, 282-294.

[31]Laal, M. (2013). Lifelong learning and technology. Procedia-Social and Behavioral Sciences, 83, 980-984.

[32] Mason, R., \& Rennie, F. (2007). Using Web 2.0 for learning in the community.The Internet and higher education, 10(3), 196-203.

[33] Požgaj, Z., \& Vlahović, N. (2010, May). The impact of Web 2.0 services on informal education. In MIPRO, 2010 Proceedings of the 33rd International Convention (pp. 944-948). IEEE.

[34] Thomas, K. J., \& Akdere, M. (2013). Social media as collaborative media in workplace learning. Human Resource Development Review, 12(3), 329-344.

[35] Sánchez-Navarro, J., \& Aranda, D. (2013). Messenger and social network sites as tools for sociability, leisure and informal learning for Spanish young people.European Journal of Communication, 28(1), 67-75. 
[36] Gu, J., Churchill, D., \& Lu, J. (2014). Mobile Web 2.0 in the workplace: A case study of employees' informal learning. British Journal of Educational Technology, 45(6), 1049-1059.

[37] Mills, L. A., Knezek, G., \& Khaddage, F. (2014). Information Seeking, Information Sharing, and going mobile: Three bridges to informal learning.Computers in Human Behavior, 32, 324-334.

[38] Casagranda, M.; Colazzo, L.; Molinari, A.; Tomasini, S.; Villa, N., "Lifelong learning implementations in virtual communities: formal and informal approaches and their impact on learners," Global Engineering Education Conference (EDUCON), 2011 IEEE, vol., no., pp.1061,1068, 4-6 April 2011 doi: 10.1109/EDUCON.2011.5773279

[39] Colomo-Palacios, R., Casado-Lumbreras, C., Soto-Acosta, P., \& Misra, S. (2014). Providing knowledge recommendations: an approach for informal electronic mentoring. Interactive Learning Environments, 22(2), 221-240.

[40] Conde, M. Á., García-Peñalvo, F. J., Rodríguez-Conde, M. J., Alier, M., Casany, M. J., \& Piguillem, J. (2014). An evolving Learning Management System for new educational environments using 2.0 tools. Interactive Learning Environments, 22(2), 188-204.

[41]F. J. García-Peñalvo, R. Colomo-Palacios, and M. D. Lytras, Informal learning in work environments: training with the social web in the workplace, Behaviour \& Information Technology, vol. 31, no. 8, pp. 753-755, 2012.

[42]F. García-Peñalvo, J. González-González, and M. Murray, Myelvin: a web-based informal learning platform for languages practice, International Journal of Knowledge Society Research (IJKSR), vol. 3, no. 1, pp. 26-39, 2012.

[43] Shepherd, C., "Does social media have a place in workplace learning?," Engineering Management Review, IEEE , vol.41, no.3, pp.40,41, Third Quarter 2013 doi: 10.1109/EMR.2013.6596530

[44] Merchant, G. (2012). Unravelling the social network: theory and research.Learning, Media and Technology, 37(1), 4-19.

[45] Madge, C., Meek, J., Wellens, J., \& Hooley, T. (2009). Facebook, social integration and informal learning at university: 'It is more for socialising and talking to friends about work than for actually doing work'. Learning, Media and Technology, 34(2), 141-155.

[46] Kimmerle, J., Moskaliuk, J., \& Cress, U. (2009, June). Learning and knowledge building with social software. In Proceedings of the 9th international conference on Computer supported collaborative learning-Volume 1 (pp. 459468). International Society of the Learning Sciences.

[47] Schroeder, J., \& Greenbowe, T. J. (2009). The chemistry of Facebook: Using social networking to create an online community for the organic chemistry laboratory. Innovate: Journal of Online Education, 5(4), 1-7.

[48]Berg, J., Berquam, L., \& Christoph, K. (2007). Social Networking Technologies: A" Poke" for Campus Services. Educause Review, 42(2).

[49] Whitty, C., \& Anane, R. (2014, January). Social network enhancement for non-formal learning. In System Sciences (HICSS), 2014 47th Hawaii International Conference on (pp. 1645-1654). IEEE.

[50] Casagranda, M.; Colazzo, L.; Molinari, A.; Tomasini, S.; Villa, N., "Lifelong learning implementations in virtual communities: formal and informal approaches and their impact on learners," Global Engineering Education Conference (EDUCON), 2011 IEEE, vol., no., pp.1061,1068, 4-6 April 2011 doi: 10.1109/EDUCON.2011.5773279

[51] Roreger, H.; Schmidt, T.C., "Socialize online learning: Why we should integrate learning content management with Online Social Networks," Pervasive Computing and Communications Workshops (PERCOM Workshops), 2012 IEEE International Conference on , vol., no., pp.685,690, 19-23 March 2012 doi: 10.1109/PerComW.2012.6197601

[52] Shi, L., Cristea, A. I., \& Hadzidedic, S. (2014, October). The critical role of profiles in social e-learning design. In Proceedings of the 15th Annual Conference on Information technology education (pp. 71-76). ACM.

[53] Santos, O.C.; Boticario, J.G., "Modelling recommendations for lifelong learning," Applications of Digital Information and Web Technologies, 2008. ICADIWT 2008. First International Conference on the , vol., no., pp.174,179, 4-6 Aug. 2008 doi: 10.1109/ICADIWT.2008.4664340

[54] Mathes, A. (2004). Folksonomies-cooperative classification and communication through shared metadata.

[55] Macgregor, G., \& McCulloch, E. (2006). Collaborative tagging as a knowledge organisation and resource discovery tool. Library review, 55(5), 291-300.

[56] Schreurs, B., \& de Laat, M. (2014). The Network Awareness Tool: A web 2.0 tool to visualize informal networked learning in organizations. Computers in Human Behavior, 37, 385-394.

[57] Drachsler, H., Hummel, H., \& Koper, R. (2008, October). Navigation support for learners in informal learning environments. In Proceedings of the 2008 ACM conference on Recommender systems (pp. 303-306). ACM.

[58] Manouselis, N., Drachsler, H., Vuorikari, R., Hummel, H., \& Koper, R. (2011). Recommender systems in technology enhanced learning. In Recommender systems handbook (pp. 387-415). Springer US.

[59] Lai, J., Lu, J., Pan, S., Soroker, D., Topkara, M., Weisz, J., ... \& Crawford, J. (2014, February). Expediting expertise: supporting informal social learning in the enterprise. In Proceedings of the 19th international conference on Intelligent User Interfaces (pp. 133-142). ACM. 
[60] Ravenscroft, A., Schmidt, A., Cook, J., \& Bradley, C. (2012). Designing social media for informal learning and knowledge maturing in the digital workplace.Journal of Computer Assisted Learning, 28(3), 235-249.

[61] Boekaerts, M., \& Minnaert, A. (1999). Self-regulation with respect to informal learning. International journal of educational research, 31(6), 533-544.

[62] Lee, B. (2013). Social Media as a Non-formal Learning Platform. Procedia-Social and Behavioral Sciences, 103, 837843.

[63] Hart-Davidson, W., McLeod, M., Klerkx, C., \& Wojcik, M. (2010, September). A method for measuring helpfulness in online peer review. In Proceedings of the 28th ACM International Conference on Design of Communication (pp. 115121). ACM.

[64] Wang, Q., Woo, H. L., Quek, C. L., Yang, Y., \& Liu, M. (2012). Using the Facebook group as a learning management system: An exploratory study.British Journal of Educational Technology, 43(3), 428-438.

[65] Jaques, E. (1996). Requisite organization: A total system for effective managerial organization and managerial leadership for the 21st century. Arlington, VA: Cason Hall.

[66] Dreyfus, H., \& Dreyfus, S. E. (2000). Mind over machine. Simon and Schuster.

[67]Bohlinger, S. (2012). Qualifications frameworks and learning outcomes: challenges for Europe's lifelong learning area. Journal of education and work,25(3), 279-297.

[68] Sampson, D., \& Fytros, D. (2008, July). Competence based Educational Metadata for supporting lifelong competence development programmes. InAdvanced Learning Technologies, 2008. ICALT'08. Eighth IEEE International Conference on (pp. 288-292). IEEE.

[69]Le Deist, F. D., \& Winterton, J. (2005). What is competence?. Human resource development international, 8(1), $27-46$.

[70]ILO: International Labour Organization - International Standard Classification of Occupations, ISCO-08. [Online; accessed 30-April- 2013].

[71]D. Hunter, ISCO-08 draft definitions, ILO Bureau of Statistics, Geneva, 2009.

[72] IMS Reusable Definition of Competency or Educational Objective (RDCEO). http://www.imsglobal.org/competencies [Online; accessed 25-March-2015].

[73] IEEE Standard for Learning Technology - Data Model for Reusable Competency Definitions," IEEE Std 1484.20.12007 , vol., no., pp.C1,26, Jan. 252008 doi: 10.1109/IEEESTD.2008.4445693

[74] HR Open Standards. http://hropenstandards.org [Online; accessed 25-March-2015].

[75] Isopahkala-Bouret, U., Rantanen, T., Raij, K., \& Järveläinen, E. (2011). European Qualifications Framework and the comparison of academically-oriented and professionally-oriented master's degrees. European Journal of Higher Education, 1(1), 22-38.

[76] Jeris, L., \& Johnson, K. (2004). Speaking of" Competence": Toward a Cross-Translation for Human Resource Development (HRD) and Continuing Professional Education (CPE). Online Submission.

[77] Kyndt, E., Govaerts, N., Verbeek, E., \& Dochy, F. (2014). Development and validation of a questionnaire on informal workplace learning outcomes: A study among socio-educational care workers. British Journal of Social Work, 44(8), 2391-2410.

[78]Lewin, K. (1946). Action research and minority problems. Journal of social issues, 2(4), 34-46.

[79] Whyte, W. F. E. (1991). Participatory action research. Sage Publications, Inc. 